\title{
Dining and nightlife in Baltimore Hot spots to visit near the Baltimore Convention Center
}

B altimore offers a wide range of eating and nightlife options, all within a short distance of the Baltimore Convention Center. They range from international avor and quality to Bal mer (or Bawlmer or Baltimore to yew outa towners we have our own way of talking here) local color establishments. These recommendations emphasize the neighborhoods that are easily reached from the Baltimore Convention Center and downtown hotels.

\section{Near the convention center}

Of course there are ne restaurants in all of the major hotels, and some

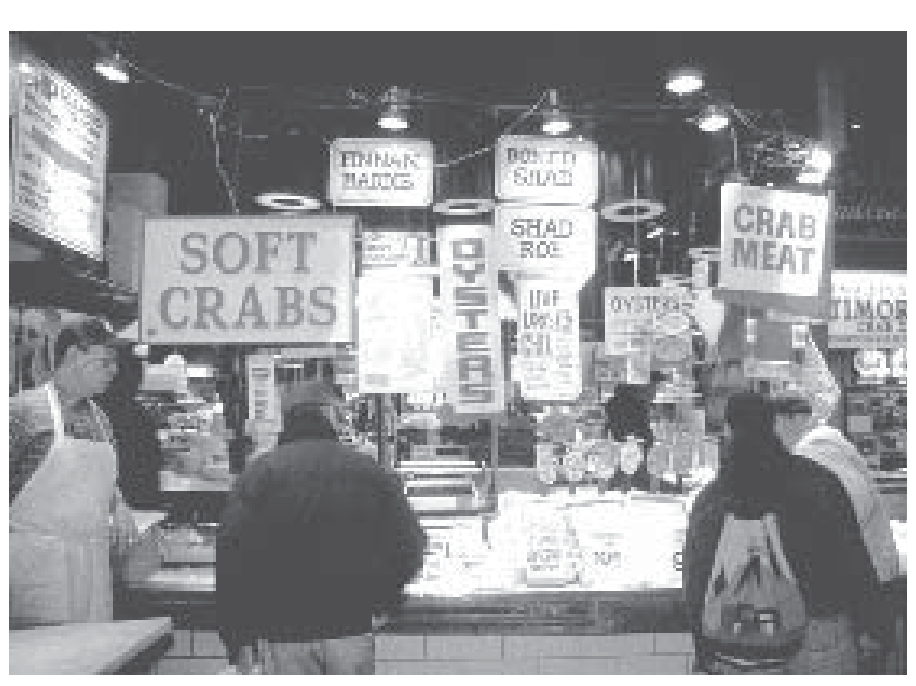

Lexington Market, which has been in business since 1782 . Credit: Baltimore Area Convention and Visitors Association. seafood dishes and sandwiches. The Wharf Rat (\$, 206 West Pratt Street, 410-244-8900, www.thewharfrat.com/) is a British style brew pub with good food and very close to the convention center; there is also a branch at 801 S. Ann Street in Fells Point.

A few blocks hike north on Eutaw Street or Paca Street will get you to the Lexington Market (www. lexingtonmarket. com/), which has been in continuous operation since 1782, with its food stalls and lots of local characters. Faidleys Seafood is a star attraction there. Or walk up Green Street to Donna's coffee shop (\$) in the University of Maryland Hospiof their chefs, like Germain Haro at the Marriott Inner Harbor, have won prizes for their creations, but we should focus here on those eating spots that are worth the effort of leaving your hotel.

There are a number of convivial sports bars, such a Pickles Pub (\$), Sliders (\$), and other small establishments, in sight of the entrance to the Camden Yards Orioles Park, where one can get a sandwich. The Luna Del Sea $(\$ \$-\$ \$$, 300 West Pratt Street, 410-7528383, www.lunadelsea.com/) is right across from the convention center. Why go farther for a quality seafood bistro? It also offers non- tal Lobby (use the main entrance at 22 Green Street) and walk past Edgar Allan Poe s grave another block north.

\section{At the Inner Harbor}

The Pratt Street Pavilion at Harborplace has several restaurants scattered among the shops. The Light Street Pavilion has plenty of walk-up fast food and a bit of seating. It also has Phillips Harborplace (\$\$-\$ \$, 410-685-

Larry Wilt is director of the library at University of Maryland-Baltimore County, e-mail:wilt@umbc.edu (c) 2007 Larry Wilt 
6600, www.phillipsseafood.com /phillipsharborplace/) for seafood and crabs. The Fudgery will entertain you while you buy some souvenir fudge.

Comedy clubs, all within walking distance of the Inner Harbor, are The Comedy Factory at Burke's Restaurant \& Café (36 Light Street, 410-547-7798, www. baltimorecomedy.com/), which also has good food ( $\$-\$ \$$ ); Winchester's Comedy Club at the Shamrock Pub (102 Water Street, 410-576-8558); and

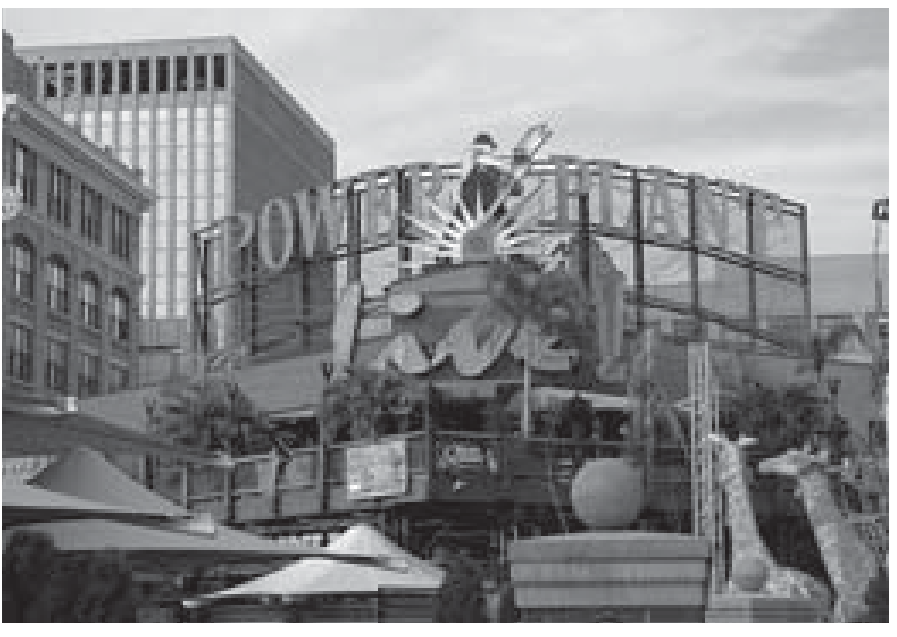

\section{Rascal's Comedy Club in the}

Power Plant (34 Market Place, 410-545-0590, www.rascalscomedyclub.com/Baltimore /baltimore.html).

Just east of the Inner Harbor, you will nd plenty of entertainment, with eating establishments scattered throughout. The Power Plant Live (34 Market Place, check the overview at www.powerplantlive.com/), has Cuban, Cajun, and other cuisines among the standard pub grub, as well as music. For national acts, make reservations in advance at Rams Head Live (www.ramsheadlive.com/). To eat, drink, and think sports, try the ESPN Zone (\$, 601 East Pratt Street, next to the National Aquarium, espnzone.com/baltimore/), in the Power Plant. Also in the Power Plant you can nd coffee, light lunch, or a book at the Barnes \& Noble bookstore (\$).

Nearby, Gardel's (\$\$, 29 S Front Street, 410-837-3737, www.gardels.com/home.htm) will give you dinner, or tapas in the bar, with a bit of dancing later in the evening. You might even be able to get a drop-in Salsa lesson there (www.dancingwithgrace. com/baltimore-salsa-lessons.html).

South of the Inner Harbor, The Rusty Scupper (\$-\$) would be good for lunch or drinks with a harbor view from the south side of the harbor. If the American Visionary Art Museum s Joy Cafe $(\$ \$)$ is reopened in time, with its great harbor view and creative menu, that would be another option. A bit further south, heading toward Fort McHenry, nd The Wine Market $(\$ \$$, 921 East Fort Avenue, 410-244-6166, www.the-wine -market.com/). You can choose any of its wine shop s selections to accompany dinner, for a modest corking fee; the upscale menu and warehouse ambiance will also delight you.

\section{Federal Hill}

Going south from the Inner Harbor either on Light Street or Charles Street, discover a wide variety of restaurants and a large number of bars, some with music, especially concentrated on Cross Street, between Light and Charles. Check the Cross Street Market (\$) for groceries or a stand-up meal while you are exploring that neighborhood. Try Spoons (\$, 24 E. Cross Street) for great coffee and breakfast. For dinner, the Blue Agave (\$\$, 1032 Light Street, 410.576.3938, www. blueagaverestaurant.com/) offers quality Mexican food and an outrageous menu of

\section{For online orientation}

The Baltimore Convention Center Web site, bccenter.org/, be sure to look at the map at bccenter.org/about /map.html.

Baltimore s tourism page, www. baltimore.org/.

The City Paper reviews, www. citypaper.com/. 
Tequilla drinks; Matsuri (\$, 1105 S. Charles Street, next to the Cross Street Market, 410752-8561, www.matsuri.us/) gets Baltimore s best sushi rating. For an upscale eclectic bistro with excellent reviews, peddle over to The Bicycle (\$\$, 1444 Light Street, 410-2341900, bicyclebistro.com/), which features 18 Wines @ \$18/btl.

\section{North Charles/Mount Vernon}

Working your way up North Charles Street from the Inner Harbor:

Sotto Sopra $(\$ \$-$ \$\$, 405 N. Charles Street, 410-625-2642, www.sottosoprainc. $\mathrm{com} /$ ) offers fine Italian cuisine in a romantic setting; try the desserts matched with wines.

The Helmand (\$\$, 806 North Charles Street, 410752-0311, www. helmand.com/) is

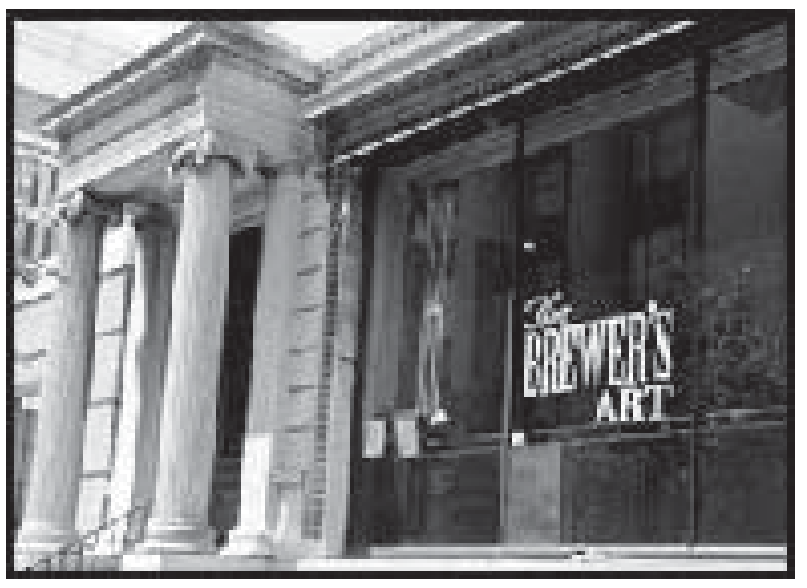

Try the Belgian-style brewpub, The Brewer's Art. Credit: (410-347-0888), which offers a great view of Baltimore and jazz at The 13th Floor (ask in the lobby what oor it is on), and the funky Owl Bar (\$), tucked behind the hotel lobby, with its brick oven pizza. Also easily reached from the Brewers Art is the Brass Elephant (\$\$-\$ \$, $924 \mathrm{~N}$ Charles Street, 410547-8480), which offers Northern Italian and contemporary American cuisine in an old Baltimore Victorian/colonial India setting. Just off Charles Street is Tío Pepe's (\$\$, 10 E. Franklin Street, 410-539-4675) a Spanish owned by a brother The Brewer's Art. of Hamid Karzai, the President of Afghanistan. The food here is international eclectic, somewhat Afghani, and a great value; try the pumpkin appetizer.

The Brewer's Art (\$-\$\$, 1106 N. Charles Street, 410-547-6925, www.belgianbeer. $\mathrm{com} /$ ), a Belgian-style brewpub with a ne restaurant (dinner only) and set in a townhouse, is rumored to have a former librarian as an owner. Even if you are going just for the superb beers, at least try the garlic fries before you head out to a nearby restaurant.

The Thai Landing ( $\$$ ) is just a block north of the Brewers Art, for those who insist on reliable Thai food after a Belgian beer. Another few blocks north, you will find Tapas Teatro $(\$ \$, 1711 \mathrm{~N}$. Charles, 410-332-1229, www.tapasteatro.net/), which offers Spanish Tapas in a cozy atmosphere. Or, going a half block south from the Brewers Art, you will reach the Belvedere Hotel
Mediterranean favorite among Baltimoreans. For beef lovers, there is the Prime Rib steak house a couple of blocks east $(\$ \$ \$$, 1101 N. Calvert Street, 410-539-1804, www.theprimerib. $\mathrm{com} /$ ). From these restaurants, closer to the harbor, nd

Club One (300 E. Saratoga Street, check their schedule at 410-230-0049, www. onebaltimore.com/index1.htm) for happy hour or a variety of music and dancing.

\section{Harbor East to Fells Point}

Going east from the harbor you rst reach Baltimore s Little Italy where you will nd some top end restaurants such as the Northern Italian Boccaccio ( $\$$ \$ \$ 925 Eastern Avenue, 410-234-1322, www.boccaccio-restaurant.com/). There are several other ne restaurants near it, like Aldo's (\$\$, 306 South High Street, 410-727-0700, www.aldositaly. com/), Chipparelli s, Ciao Bella, DaMimmo s, Della Note, and India Rasoi (411 South High Street, 410-385-4900), the best Punjabi Indian Restaurant in Little Italy good for veggies and non-veggies), all within walking distance of the Inner Harbor. See www.littleitalyrestaurants.com/ for more information. Consider heading to Vaccaro's Italian Pastry Shop (\$, 222 Albemarle Street, 410-685-4905, www. 
vaccarospastry.com/) for a sinful dessert regardless of where you have dinner.

Visit Pazo Restaurant (\$\$-\$\$, 1425 Aliceanna Street, 410-534-7296, www.pazorestaurant.com/) for Tapas-inspired delicacies with a Mediterranean-in uenced cuisine in stylish atmosphere; Baltimoreans are still discovering this gem that is on the way to Fells Point. Also in this area, literati may enjoy the Irish food and ambiance, with music most nights, at The James Joyce Pub (\$\$, 616 President Street, 410727-5107, thejamesjoycepub.com/pub.html).

South Broadway, starting about four blocks north of the water at Eastern Avenue, has not yet been dubbed Little Hispania but is developing into a center for Latin American restaurants. Try, for example, Restaurante Arcos (\$\$, 129 S. Broadway, 410-522-4777) and there are several others nearby where they hablan español. Or try Cantonese, Shanghai, and Szechuan dishes at Ding How (\$\$, 631 S. Broadway, 410-3278888) You can relax at Ze Mean Bean (1739 Fleet Street, 410-675-5999, www.zemeanbean. com/), a coffee house with Eastern European cuisine, wine and desserts. For a nonsmoking American-French bistro, try the Timothy Dean Bistro (1717 Eastern Avenue, 410-534-5650, www.tdbistro.com/about.html).

At the high end, Fells Point offers the acclaimed Charleston ( $\$ \$ \$ \$, 1000$ Lancaster Street, 410-332-7373, www. charlestonrestaurant.com/), Black Olive for quality Greek organic ( $\$ \$ \$-\$ \$ \$$, 814 Bond Street, 410-276-7141, www.theblackolive. com/), Kali's Court Restaurant (\$\$, 1606 Thames Street, 410-276-4700, www.kaliscourt. com/home.php) for Mediterranean-in uenced dishes with great seafood choices, and Louisiana (\$\$, 410-327-2610, www.louisianasrestaurant.com/home.html) for elegant, Creole-style southern cuisine; the Antebellum-esque setting goes perfectly with the rich menu choices. Try the crab bisque.

There are too many bars to crawl in the Fells Point neighborhood, especially on Thames Street and South Broadway. Some highlights are: Bertha's (\$\$, 734 S. Broadway, 410-3275795, www.berthas.com/) for classic Balmer atmosphere; try their afternoon tea with tarts and scones; get an Eat Bertha s Mussels bumpersticker. The Full Moon Saloon (\$, 410-276-6388, 1710 Aliceanna Street, www. fullmoon-saloon.com/), serves up live blues and pub food seven nights per week; The Cat's Eye Pub (\$, 1730 Thames Street, pronounced theyms here, 410-276-9866, www.catseyepub. com/) offers pub food with zydeco, blues, etc., in an Irish Pub setting, across from the outdoor setting of the television show Homicide: Life on the Street. The young and daring might gravitate to The Horse You Came In On (\$, 1626 Thames Street 410-327-8111, horsesaloon.com/) or Max's (\$, 737 S. Broadway, 410-675-6297, www.maxs.com/), which has more beer taps than anyone needs.

Of course we cannot overlook Fells Point s brew pubs: The Wharf Rat ( $\$$, branch location at 801 South Ann Street, 410-276-9034), and DuClaw (\$, 901 S. Bond Street, 410-563-3400). If you are still bumping around this neighborhood the next morning or as late as 3 p.m., stop at the Blue Moon Café (\$, 1621 Aliceanna Street, 410-522-3940) for breakfast; it is also nice for lunch daily, for after 11 p.m. dinner on Fridays and Saturdays, and for vegetarian selections.

The Broadway Market, in the heart of Fells Point, is good for a sandwich or snack. Closer to the Inner Harbor, you can nd quality groceries and sandwiches at the Whole Foods Market (1001 Fleet Street).

Steamed crabs and crab cakes are Bal mer specialties. To get these in a Bal mer atmosphere, try Obrycki's (\$\$, 1727 E. Pratt Street, 410-732-6399, www.obryckis.com/obr/stores/1/ index.cfm) just past Broadway. And, somebody has whispered that you can get a better-thanpub-grub crab cake at Duda's Tavern (\$, 1600 Thames Street, 410-276-9719), also good for burgers and kegs of quality brews.

Just east of Fells Point, newly trendy Canton has recently developed as a center of entertainment and restaurants. It is reachable by water taxi or land taxi. On O Donnell Square, try Helen's Garden (\$\$-\$\$, 410-2762233, www.helensgarden.com/V2/) for great food and stellar wines in a relaxed setting, Mama's on the Half Shell (\$\$-\$\$, www. mamasonthehalfshell.com/) for a laid back 
seafood place with a good atmosphere, or Birches (\$\$-\$\$, 410-276-3160, www. birchesrestaurant.com/) for contemporary American cuisine with an inviting and comfortable setting. Both football fans (there is a TV at each booth) and Alabama-style barbeque fans will like Ray Lewis Full Moon Bar-B-Que (\$\$, 2400 Boston Street, 410-327-5200). The Austin Grill (\$\$, 410-534-0606, www.austingrill.com) is a Tex Mex place at the same location; it has music on Fridays and Saturdays, usually after 9 p.m.

\section{Farther afield, but worth the trip}

If you get north to 36th Street in colorful Hampden, a funky, artsy shopping opportunity near The John Hopkins University campus, try Café Hon (\$-\$\$, 1002 W. 36th Street 410-243-1230, www.cafehon.com/) for Bal mer atmosphere and avor (Web site includes a primer on Bawlmerese language). Across the street is Suzie's Soba 1 (\$\$, 1009 W. 36th Street, 410-243-0051), which offers a creative menu of fusion Asian dishes, especially featuring a variety of noodles and some very nice desserts. Next door at Grill Art (\$\$-\$\$, 1011 W. 36th Street, 410-366-2005), you can do sandwiches, an entr e-sized salad, or a full dinner. A funky atmosphere and a New Mexico meets Far East menu will intrigue you at the Golden West Café (\$-\$\$, 1105 W. 36th Street, 410-889-8891, goldenwestcafe.com/), just a block away; try the polenta or the chorizo burritos breakfast is served all day.

The Baltimore Museum of Art has Gertrude's (\$\$-\$\$, 410-889-3399, www. johnshields.com/restaurant/rest/gertrudes.html) for the after-museum lunch or dinner or try their brunch on Saturday or Sunday.

Note on reservations: Be sure to reserve ahead. Some of the more popular places may be booked two weeks to a month in advance, especially when a conference is in town.

And nally, when all else fails, ask a librarian: There are many other worthwhile restaurants in the Bal mer area; just nd some local librarians at the conference and get them started. $=2$

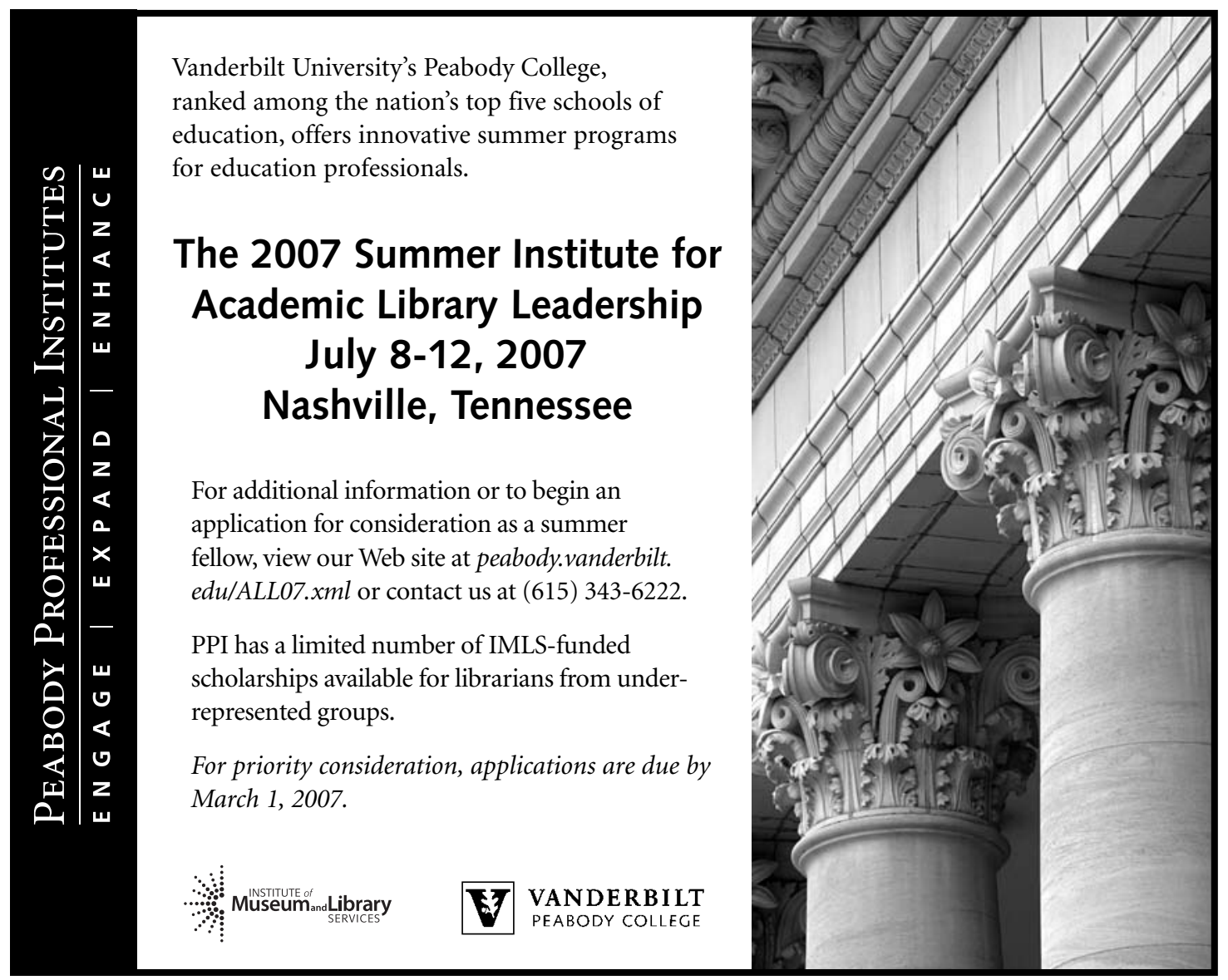

